\title{
Nanomechanical properties of C-S-H gel/cement grain interface by using nanoindentation and modulus mapping*
}

\author{
Jing $\mathrm{XU}^{\dagger 1}$, David J. CORR ${ }^{2}$, Surendra P. SHAH ${ }^{2}$ \\ $\left({ }^{1}\right.$ Key Laboratory of Advanced Civil Engineering Materials of Ministry of Education, Tongji University, Shanghai 201804, China) \\ $\left({ }^{2}\right.$ Department of Civil and Environmental Engineering, Northwestern University, Evanston, IL 60208, USA) \\ ${ }^{\dagger}$ E-mail: 0610060014@tongji.edu.cn \\ Received June 5, 2014; Revision accepted Oct. 14, 2014; Crosschecked Dec. 18, 2014
}

\begin{abstract}
Investigation on the mechanical properties of cement-based materials at micron and sub-micron scales is important for understanding its overall performance. Recent progress in experimental nanomechanics opens new access to nanoengineering of cement-based composites. In this study, nanoindentation and viscoelastic modulus mapping were employed to study the interfacial properties. The interface width measured by modulus mapping was around $250 \mathrm{~nm}$ as compared to a rough estimation of less than $5 \mu \mathrm{m}$ by nanoindentation, due to the fact that 2 orders of magnitude increase in spatial resolution could be achieved by modulus mapping. Both the nanoindetation and modulus mapping results indicated that the modulus of the interface falls between 60-70 GPa. The packing density in the interface was non-uniform as two peaks of value were observed for the storage modulus distribution. This interface could be regarded as a dense hydration coating around cement grains, which was less permeable and hindered the further hydration of cement.
\end{abstract}

Key words: Cement-based materials, Nanomechanical properties, Interface, Modulus mapping doi:10.1631/jzus.A1400166 Document code: A CLC number: TU502

\section{Introduction}

Concrete is known as a multi-phase composite material in multiple scale levels. The heterogeneity can be estimated by a three-level model (Constantinides and Ulm, 2004; Xu and Yao, 2011). In level I $\left(10^{-2}-10^{0} \mathrm{~m}\right)$ and level II $\left(10^{-4}-10^{-2} \mathrm{~m}\right)$, the material can be viewed as a three-phase system: matrix, coarse or fine aggregate dispersed as strengthened particles, and the aggregate/matrix interfacial transition zone (ITZ). For level III $\left(10^{-6}-10^{-4} \mathrm{~m}\right)$, the C-S-H gel together with large $\mathrm{Ca}(\mathrm{OH})_{2}$ crystals, unhydrated cement clinker and micro-pores form the cement paste. At this level, the unhydrated cement grains act as a strengthened hard phase distributed in

\footnotetext{
* Project supported by the National Natural Science Foundation of China (No. 51378011)

(B) ORCID: Jing XU, http://orcid.org/0000-0003-4130-066X

(c) Zhejiang University and Springer-Verlag Berlin Heidelberg 2015
}

the matrix of hydration products, which is mainly composed of C-S-H gel. Accordingly, the presence of interfaces between C-S-H and unhydrated cement grains should be taken into account.

For levels I and II, the interfacial phases are generally well accepted and understood, due to the relatively large characteristic length scale of constituents that can be directly observed by microscopy imaging techniques. However, to the best of our knowledge, there is no report that investigates the microscopic mechanical properties across the interface between cement grains and C-S-H gel in level III. Previous studies are mainly restricted to C-S-H phase or cement clinker (Acker, 2001; Constantinides et al., 2003; 2006; Constantinides and Ulm, 2007; DeJong and Ulm, 2007; Jennings et al., 2007; Mondal et al., 2007; 2008; Vandamme et al., 2010; Davydov et al., 2011; Jones et al., 2012). This interfacial phase may play important roles across the boundary for joining mechanically dissimilar 
materials, i.e., cement grains and C-S-H gel, and thus an in-depth investigation is needed.

With the development of new techniques and instruments, one can explore the mechanical properties of materials at the nano- and micro-scale, such as the behavior under loading, the initiation of microcracking and fracture, and even the phase characteristics. Two different techniques have been developed by 'Triboindenter', which is commercially available, for these studies (Velez et al., 2001): the depth sensing nanoindentation and quantitative modulus mapping in the form of scanning probe microscopy (SPM). Nanoindentation is a 'destructive' strategy while modulus mapping is considered 'nondestructive'. In this study, the elastic modulus and hardness of cement paste composite are evaluated using nanoindentation with the addition of modulus mapping. The local variation of nanomechanical properties within the interface between cement grains and C-S-H gel is reported.

\section{Experimental}

\subsection{Sample preparation}

Type I Portland cement was used throughout. Cement paste with a water-to-cement ratio $(\mathrm{w} / \mathrm{c})$ of 0.28 was prepared. The samples were cast in prismatic molds of $5 \mathrm{~mm} \times 5 \mathrm{~mm} \times 15 \mathrm{~mm}$. After $24 \mathrm{~h}$ curing in a $100 \%$ humidity room with temperature of $(20 \pm 2){ }^{\circ} \mathrm{C}$, the samples were demolded and then further cured for $27 \mathrm{~d}$. At the end of curing, the $15 \mathrm{~mm}$ thick samples were then cut into approximately $3 \mathrm{~mm}$ thick slices with a diamond saw. The cut slices were immersed in ethanol for $24 \mathrm{~h}$ to stop further hydration. Then the slices were removed from the ethanol and were subjected to a heat treatment (drying) of $60^{\circ} \mathrm{C}$ for $24 \mathrm{~h}$. Three slices were selected for the subsequent sample preparation and testing.

For a reliable measure of the local mechanical properties, the sample must have a flat and smooth surface. All the samples were initially ground on Buehler-Met II paper disks with a gradation of 34.2, $22.1,14.5$, and $6.5 \mu \mathrm{m}$, successively. Approximate grinding time on each gradation was $5 \mathrm{~min}$ and water was used as the cooling medium and lubricant. In the following steps, Buehler diamond suspensions in ethanol of gradations $6,3,1$, and $0.3 \mu \mathrm{m}$ were used as polishing liquids on a Buehler Consumables Texmat cloth. The polishing time was $30 \mathrm{~min}$ for each of the diamond polishing steps. Finally, an ultrasonic bath cleaning in ethanol was performed for $10 \mathrm{~min}$ to remove all dust and diamond particles. Samples were stored in a container after preparation and the surface quality was confirmed by optical microscopy.

The polished samples were further evaluated by atomic force microscopy (AFM, Bruker AXS Dimension ICON, Germany) to obtain the surface topographic information. All the samples were scanned using the tapping mode to obtain a topographic map, and the scanning was performed with an amplitude set point of $250 \mathrm{mV}$ and a scan rate of $0.75 \mathrm{~Hz}$. A total of five scans were conducted on each sample surface. Following the imaging procedure, each image was digitally analyzed to extract a roughness value. Before calculating the roughness, a linear slope correction was performed to account for an alignment difference between the reference plane of AFM imaging and the overall slope of the sample surface. The preferred parameter for roughness was a root-mean-squared (RMS) average of the topography of the surface $\left(R_{\mathrm{q}}\right)$. The AFM results of roughness provide a reference for the following nanomechanical tests.

\subsection{Nanoindentation and modulus mapping}

Nanoindentation and modulus mapping experiments were performed with a TriboScope nanomechanical testing system (Hysitron, Minneapolis, USA) equipped with an in situ imaging mode. The nanoindentation instrument consists of a force displacement transducer with electrostatic force actuation and displacement sensing electronics. A Berkovich indenter was used, which is a three-sided pyramid with a total included angle of $142.3^{\circ}$ and a tip radius, which is determined to be $600 \mathrm{~nm}$ by standard nanoindentation protocol. During indentation, the indenter came into contact with the sample surface with a trapezoidal load function, as defined by a loading time of $5 \mathrm{~s}$, a holding time of $2 \mathrm{~s}$ at a maximum load of $1.2 \mathrm{mN}$, and an unloading time of $5 \mathrm{~s}$. Fig. 1 presents typical load-depth curves of cement grains and C-S-H gel. Irregular nanoindentation curves due to the presence of voids and cracking of the sample were discarded. By applying a continuum scale model, the initial unloading stiffness $S$ is given as

$$
S=\frac{\mathrm{d} p}{\mathrm{~d} h}=\frac{2}{\sqrt{\pi}} E_{\mathrm{r}} \sqrt{A},
$$


where $p$ is the load, $h$ is the displacement, $A$ is the projected contact area at the peak load $P_{\max }$ and can be extrapolated by the Oliver and Pharr method (Oliver and Pharr, 1992; 2004), and $E_{\mathrm{r}}$ is the reduced elastic modulus, which can be determined by nanoindentation. Then the elastic modulus $E$ of the sample can be calculated by

$$
E=\left(1-v^{2}\right) /\left[\frac{1}{E_{\mathrm{r}}}-\frac{\left(1-v_{\mathrm{i}}^{2}\right)}{E_{\mathrm{i}}}\right],
$$

where $E_{\mathrm{i}}$ and $v_{\mathrm{i}}$ are Young's modulus and Poisson's ratio of the indenter, respectively. For the indenter used in the present experiment, the elastic modulus $E_{\mathrm{i}}=1140 \mathrm{GPa}$ and Poisson's ratio $v_{\mathrm{i}}=0.07 . v$ is Poisson's ratio of the sample. The suggested value of $v$ is 0.24 , which was used in this study to calculate $E$ (Sorelli et al., 2008). The hardness $H$ has the definition of

$$
H=\frac{P_{\max }}{A} .
$$

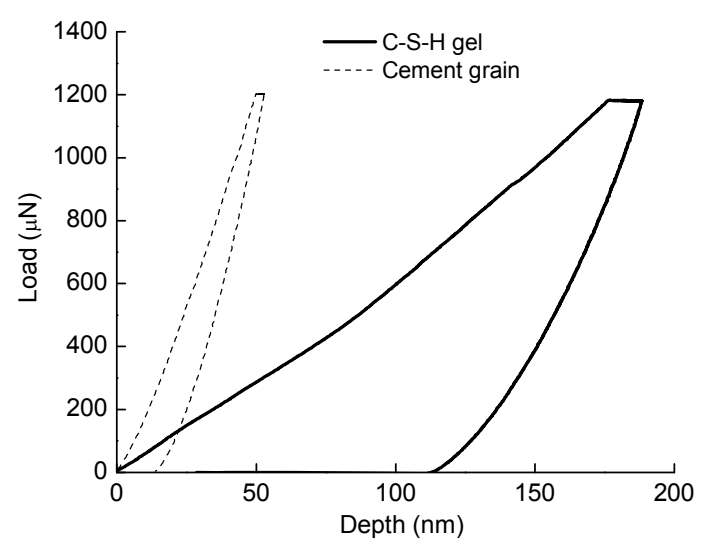

Fig. 1 Typical load-depth curves of nanoindentation on different phases in cement paste

Statistical grid nanoindentation tests were carried out across the interface between unhydrated cement grain and the C-S-H gel. The spacing between the indents was $3 \mu \mathrm{m}$ and $5 \mu \mathrm{m}$ in the lateral and vertical directions, respectively. The indent areas had the dimensions of $30 \mu \mathrm{m} \times 10 \mu \mathrm{m}$ (Fig. 2). Therefore, 33 indents were performed at each studied area. An optical microscope was used to observe the surface morphology and place the indents on desired locations. After indentation, the in situ SPM imaging was performed to obtain the surface topography using a very light loading force $(2 \mu \mathrm{N})$ without causing any damage to the surface.

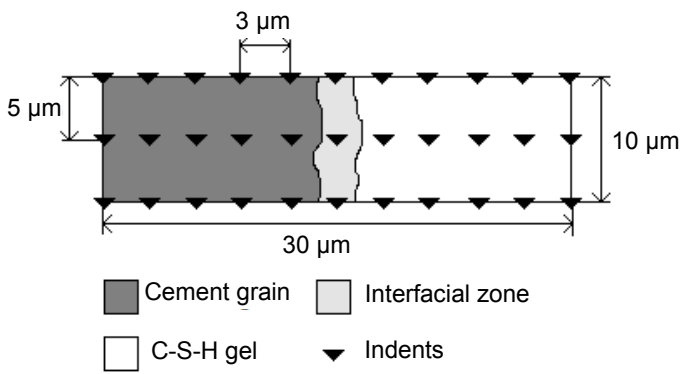

Fig. 2 Grid nanoindentation across the interface between C-S-H gel and cement grain

Quantitative modulus maps in the form of SPM images were acquired using the direct force modulation (nanoDMA) operating mode of a TriboScope nanoindenter. The advantage of force modulation is that the contact stiffness can be directly obtained continuously during indentation, thus forming a modulus mapping, which could be an ideal technique for multiphase and composite materials. In force modulation, a $8 \mu \mathrm{N}$ quasi-static force (DC force) was superimposed by a $3.5 \mu \mathrm{N}$ sinusoidal force ( $\mathrm{AC}$ force) with a frequency of $200 \mathrm{~Hz}$. A lock-in amplifier was utilized to analyze the sample response, yielding displacement amplitude and the phase shift between the $\mathrm{AC}$ force and the displacement. The contact stiffness and material damping were calculated from the amplitude and phase shift using a dynamic model. A review of quantitative modulus mapping implementation details can be found in (Balooch et al., 2004; Uskokovic et al., 2007). Before modulus mapping measurements, in situ SPM was employed to identify one specific unhydrated cement grain. Modulus mapping with a scanning size of $15 \mu \mathrm{m} \times 15 \mu \mathrm{m}$ was carried out across the interface between the unhydrated cement grain and the C-S-H gel.

\section{Results and discussion}

\subsection{Nanoindentation}

To ensure the accuracy of nanoindentation results, the indentation depth should be larger than the RMS roughness. In this study, the nanoindentation was performed on two distinctive phases: unhydrated 
cement grain and hydration products (mainly C-S-H gel). According to Miller et al. (2008), the scanning size should be at least 200 times the average depth, which was $180 \mathrm{~nm}$ on hydration products as compared with $60 \mathrm{~nm}$ on cement grains. Thus, the scanning sizes on hydration products and cement grains were selected as $40 \mu \mathrm{m}$ and $15 \mu \mathrm{m}$, respectively. A comparison of the $3 \mathrm{D}$ topography images obtained by the AFM at hydration products and cement grains is presented in Fig. 3. The mean RMS values of five scans at each location of the sample are shown in Table 1. The average indentation depth on both of the hydration products and cement grains is larger than surface roughness by an order of 3 , which is sufficient to avoid effects of roughness (Xiao et al., 2013).

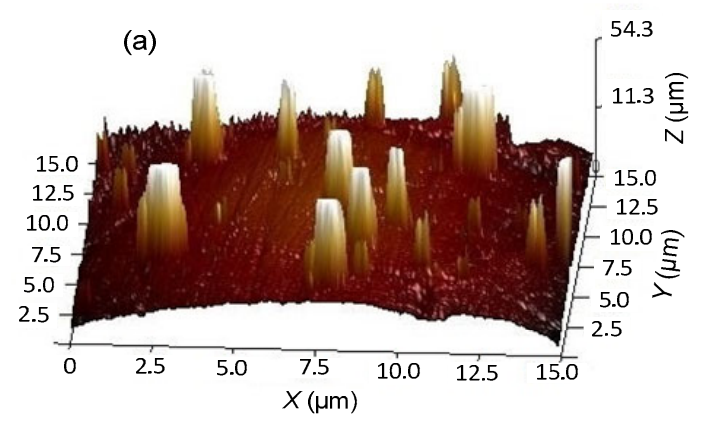

(b)

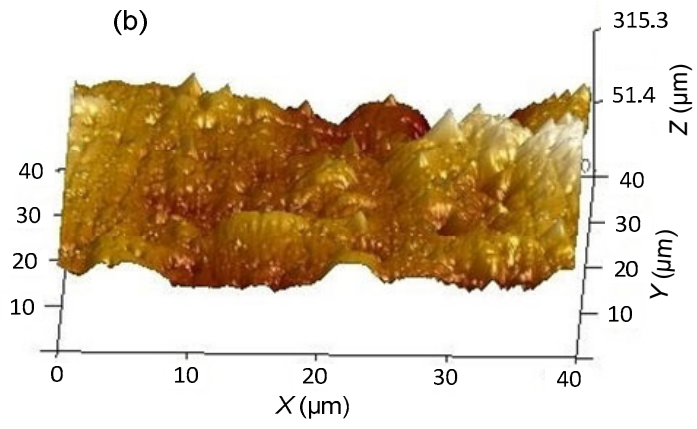

Fig. 3 AFM 3D topography images on cement paste

(a) Cement grain; (b) C-S-H gel

Table 1 RMS roughness measurement for multiple phases in cement paste

\begin{tabular}{cccc}
\hline $\begin{array}{c}\text { Scanning } \\
\text { location }\end{array}$ & $\begin{array}{c}\text { Scanning } \\
\text { size }(\mu \mathrm{m})\end{array}$ & $\begin{array}{c}\text { Average } \\
\text { indentation } \\
\text { depth }(\mathrm{nm})\end{array}$ & $\begin{array}{c}\text { Average } \\
\text { RMS rough- } \\
\text { ness }(\mathrm{nm})\end{array}$ \\
\hline $\begin{array}{l}\text { Hydration prod- } \\
\text { ucts (mainly } \\
\text { C-S-H gel) }\end{array}$ & $40 \times 40$ & $180.3 \pm 6.1$ & $59.4 \pm 17.0$ \\
\begin{tabular}{c} 
Cement grains \\
\hline
\end{tabular} & $15 \times 15$ & $57.8 \pm 3.8$ & $12.7 \pm 7.3$ \\
\hline
\end{tabular}

Fig. 4a shows the area on cement paste that contain the interface between the cement grain and C-S-H gel that was selected for grid indentation by optical microscope. Results of indentation modulus and hardness distributions with the distances across interfacial region are shown in Fig. 4b. The modulus and hardness of C-S-H gel were found to be between 20-40 GPa and 1-2 GPa, respectively, depending on the density of C-S-H. This is consistent with previous studies (Acker, 2001; Velez et al., 2001; Constantinides and Ulm, 2004; DeJong and Ulm, 2007; Mondal et al., 2007; Sorelli et al., 2008). Modulus and hardness varied in the cement grain, which could be pure clinker phase or the particle edge and void regions in the boundary of pure phases within the cement grain. The interface was estimated by the sharp decrease in indentation modulus and hardness with the distance from the cement grain. The interface width was roughly estimated as less than $5 \mu \mathrm{m}$. The mean values of indentation modulus and hardness of the interface were observed as $68 \mathrm{GPa}$ and $3 \mathrm{GPa}$, respectively.
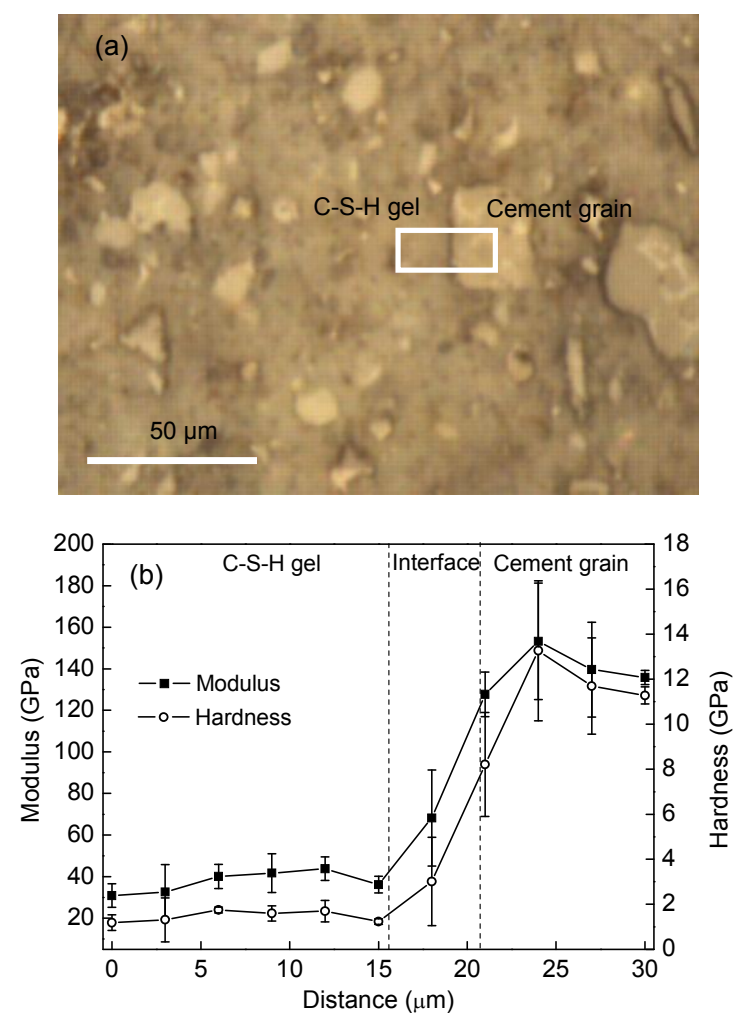

Fig. 4 Grid nanonindentation results on interface between C-S-H gel and cement grain

(a) Optical image; (b) Modulus and hardness vs. position 
Grid indentation performed across the cement grain/C-S-H gel interface can generate enough data without any bias for a statistical analysis. The interface region belongs to the C-S-H gel matrix; however, the apparent higher values of modulus and hardness showed matrix hardening in the vicinity of the cement grain, probably due to the influence of deformation fields of the cement grain and the C-S-H gel phase, i.e., a confinement effect by hard particles. It should be pointed out that there are limitations in discrete nanoindentation. For Berkovitch diamond tips, the lateral dimension of the indentation is greater than the depth of indentation. Therefore, to avoid errors in results due to possible overlapping or interaction between adjacent indentations, a separation is needed. For multi-phase materials with large differences in mechanical properties, such as the cement paste, the softer material dictates the minimum separation required, as the indentations in the hard phase are far apart, while in the soft part they tend to touch one another. As shown in Fig. 5, the lateral dimension of an indent mark on soft C-S-H gel was about $1-2 \mu \mathrm{m}$. Thus, a minimum separation of $3 \mu \mathrm{m}$ was selected to avoid the interaction. Subsequent modulus mapping results showed that the interface size was far less than $1 \mu \mathrm{m}$. Thus, the interface thickness cannot be accurately probed by nanoindentation, and a best estimate of less than $5 \mu \mathrm{m}$ was determined using this technique.

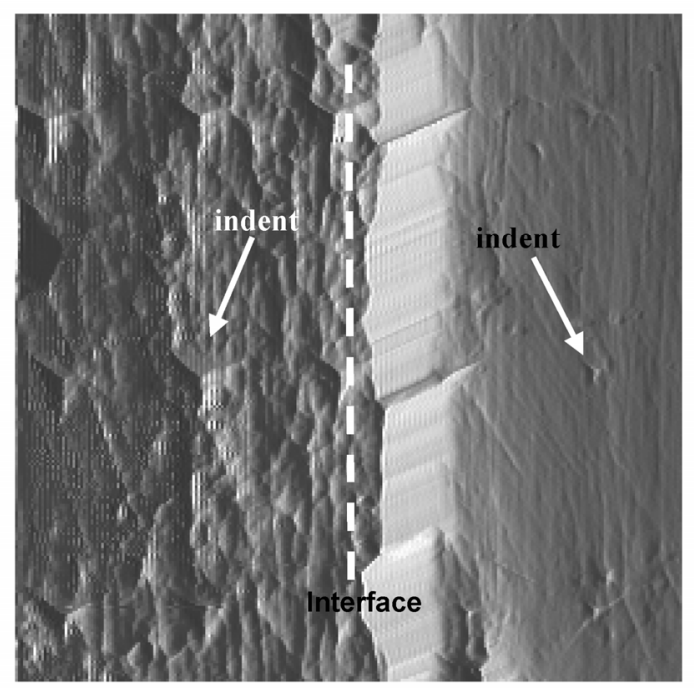

Fig. 5 In situ image of the indents near interface (the left and right arrows indicate the indents on C-S-H gel and cement grain, respectively)

\subsection{Modulus mapping}

The image capability of the Triboindenter can provide an effective method for examining different phases. Fig. 6 shows a topographical map of the area in cement pastes, which contains the cement grain, interface, and C-S-H gel, as obtained by SPM. The color scale is proportional to the height variation $(z-$ scale of $1500 \mathrm{~nm}$ ). Close to the interface a step in height resulted from polishing.

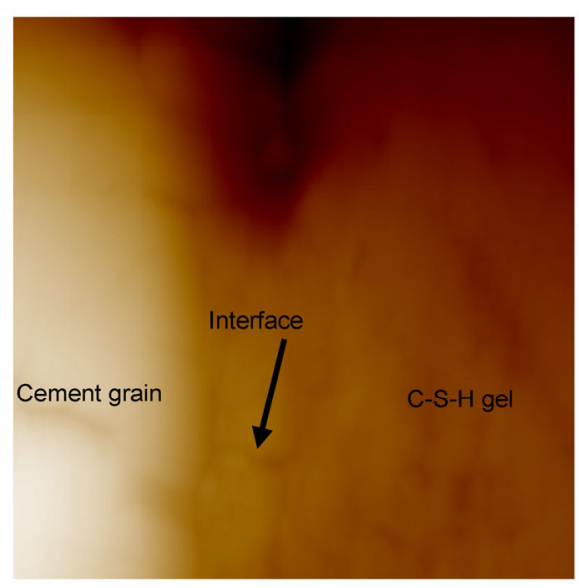

Fig. 6 SPM topography image of interface between $\mathrm{C}-\mathrm{S}-\mathrm{H}$ gel and cement grain

Fig. 7a presents the contact force image of the area as displayed in Fig. 6, calculated from the measured displacement and previously calibrated transducer spring constant. The average force across the scan was held at $8 \mu \mathrm{N}$. The variation in the C-S-H gel area was larger than in the cement grain since the feedback error signal was more active due to the rougher surface. Fig. $7 \mathrm{~b}$ represents the displacement amplitude, and Fig. 7c shows the phase difference between the displacement modulation and the applied force modulation. The amplitude was about $0.7-1.0 \mathrm{~nm}$ for C-S-H gel as compared to $0.5-0.6 \mathrm{~nm}$ in the cement grain (Fig. 7d).

Knowing these phase differences and amplitude variations of modulation, along with the spring constant and damping coefficient of the transducer, the storage and loss moduli of the area were calculated, and displayed as an image with a selected line scan in Fig. 8. For the C-S-H gel, the loss modulus was comparable to the storage modulus; for the cement grain, however, the loss modulus was much lower 


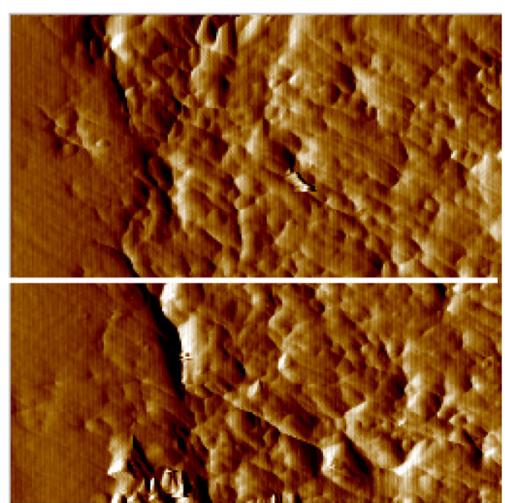

(a)

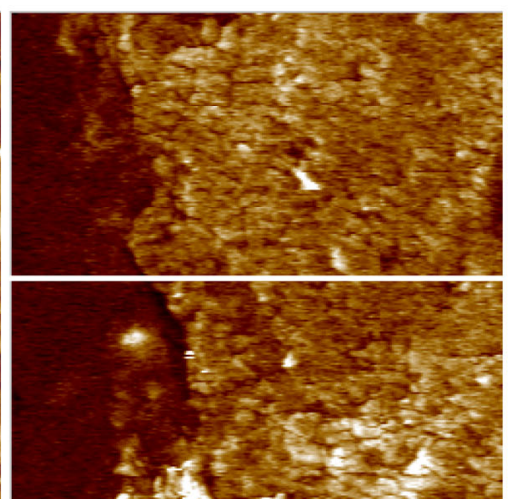

(b)

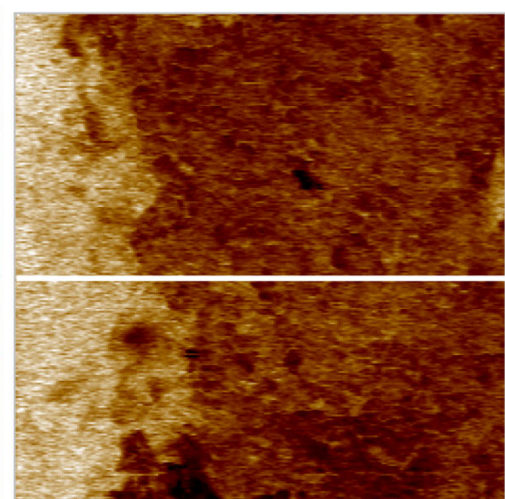

(c)

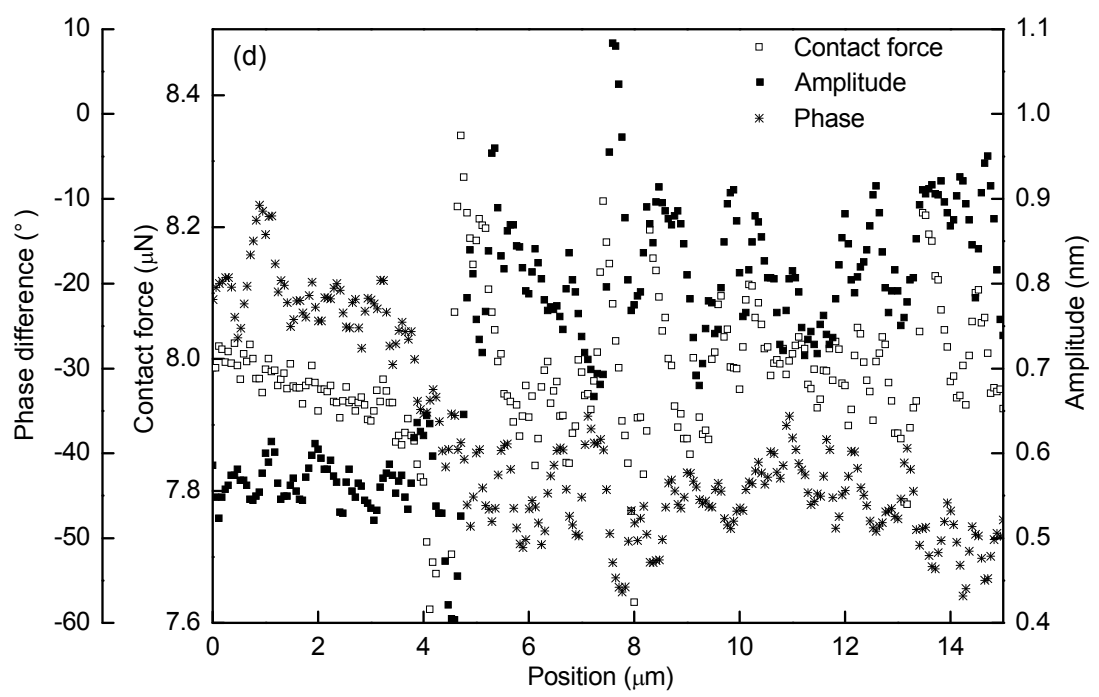

Fig. 7 Images of contact force (a), displacement amplitude (b), and phase (c), and variations at specific cross section (d) of the interface (white line indicates the cross section)

(a)

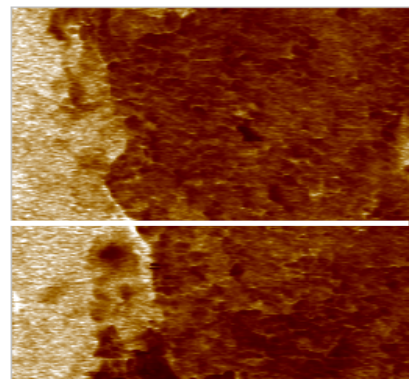

(b)

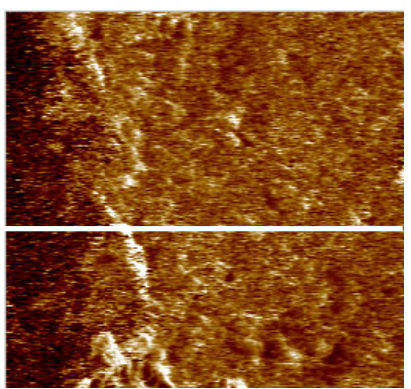

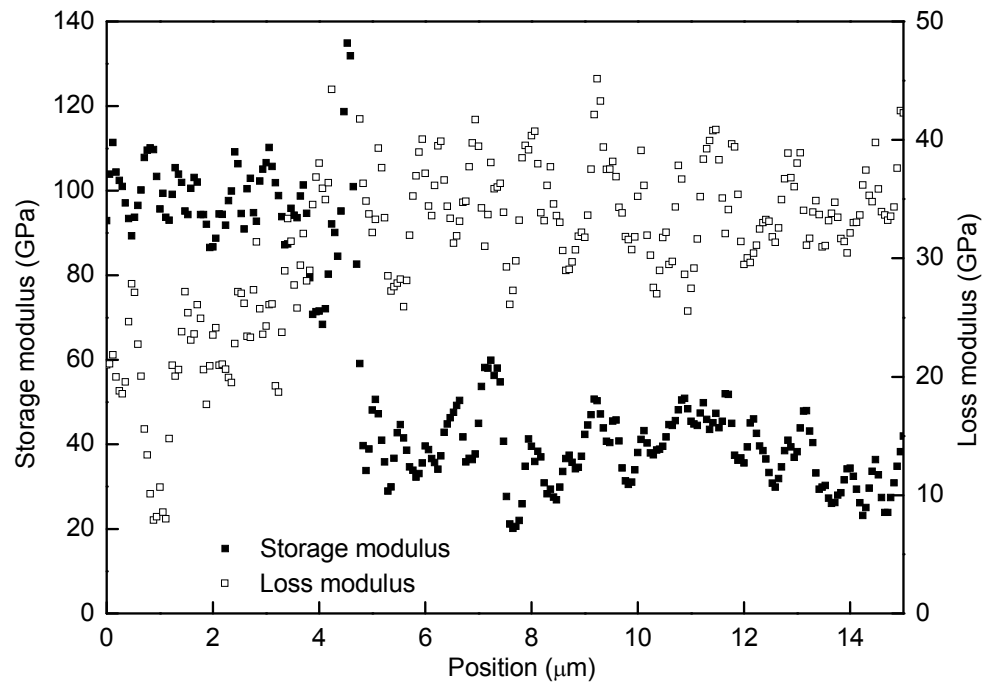

(c)

Fig. 8 Images of storage (a) and loss (b) modulus, and variations at specific cross section (c) of the interface (white line indicates the cross section) 
than the storage modulus. The damping coefficient was larger for the C-S-H gel than the cement grain, suggesting that the gel is more viscoelastic. This is a result of higher energy dissipation as heat while the $\mathrm{C}-\mathrm{S}-\mathrm{H}$ gel is deformed in comparison with cement grains. The higher loss modulus makes C-S-H less prone to fracture. Appreciable local variations in both gel and cement grain were evident from the cross sections drawn across the interface (Fig. 8c). Compared with the loss modulus, a more significant difference between gel and cement grain could be observed for the storage modulus. The $\mathrm{C}-\mathrm{S}-\mathrm{H}$ gel storage modulus variation was between 20 and $50 \mathrm{GPa}$. The range of storage modulus for the cement grain was between 90 and $110 \mathrm{GPa}$. The storage modulus ranges of C-S-H gel and cement grain corresponded well with the ranges of elastic modulus by nanoindentation, which could be due to the fact that the storage modulus represents part of the elastic response of the material.

In modulus mapping mode, the material under the tip is probed within the elastic region. Once the tip force is removed, the material returns to its original shape with no local residual stress or permanent deformation. The current technique can only be used to determine mechanical property variation in a small area (maximum of $50 \mu \mathrm{m} \times 50 \mu \mathrm{m}$ ). This can be extremely useful when investigating narrow transition zone widths and local variations of a local mechanical property; however, for larger areas, this technique would be inconvenient and timeconsuming, because a typical scan of $15 \mu \mathrm{m} \times 15 \mu \mathrm{m}$ takes $45 \mathrm{~min}$. Since the probing remained in the elastic region, the spatial resolution depended only on the radius of the tip and the contact area. The tip radius was determined to be $600 \mathrm{~nm}$ by standard nanoindentation protocol. Thus, the contact area can be given as

$$
a=\sqrt{\frac{3 F R}{2 K^{\prime}}},
$$

where $F$ corresponds to the nominal contact force, $R$ is the tip radius, and $K^{\prime}$ is the contact stiffness. Values of the contact radius were $56 \mathrm{~nm}$ for the C-S-H gel and $40 \mathrm{~nm}$ for the cement grain, which were sufficiently smaller than the step size in modulus map- ping to ensure the validity of the results (Table 2).

Table 2 Comparison of nanoindentation and modulus mapping

\begin{tabular}{ccc}
\hline Method & Contact force $(\mu \mathrm{N})$ & Step size $(\mathrm{nm})$ \\
\hline Nanoindetation & 1200 & 3000 \\
Modulus mapping & 8 & 60 \\
\hline
\end{tabular}

Compared with nanoindentation, modulus mapping allowed evaluation of both storage and loss moduli for small areas with high spatial resolution (Table 2). Furthermore, due to the significant variation of the storage moduli across the interface in modulus mapping, curves of the storage modulus could be used to determine the width of interface as shown in Fig. 9. The data was analyzed by sigmoidal curve fitting. A tangent line with the inflexion point of the curve as the tangent point could be drawn, resulting in two intersections with the extension of base lines, and the region between the two intersections was the interface. By measuring the change in properties across 256 cross-sectional lines accessible on a single image, the function is shown in Fig. 10. A Gaussian distribution function was used to fit the data, and the most probable width of the interface was found to be $0.25 \mu \mathrm{m}$. This is one order of magnitude lower than the results from nanoindentation, which further validates the higher accuracy of probing by modulus mapping. Meanwhile, the mean value of the interface at each cross-sectional line was also calculated. The distribution functions for all samples studied are shown in Fig. 11. Two peaks were observed for the modulus distribution of the interface, suggesting the non-uniform packing density of the interface. Values of the storage modulus of the interface were $61.5 \mathrm{GPa}$ and $68.3 \mathrm{GPa}$, which are comparable with the nanoindentation result. The interface studied by nanomechanical measurements in this study could be considered as a coating layer on cement grains. This was further verified by scanning electron microscopy (SEM) images (Fig. 12). Previous research showed that a dense coating was formed on unhydrated cement particles, which was less permeable and hindered the further hydration of cement (Kawashima et al., 2013). Therefore, the interface studied by nanomechanical measurements in this study could be considered as this coating layer on cement grains. 


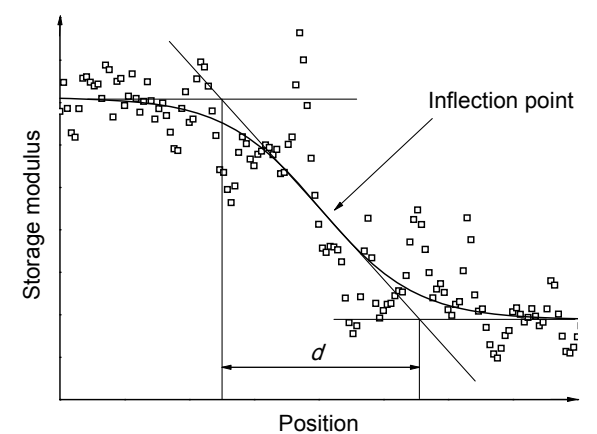

Fig. 9 Determination of interface width $(d)$ by storage modulus curve

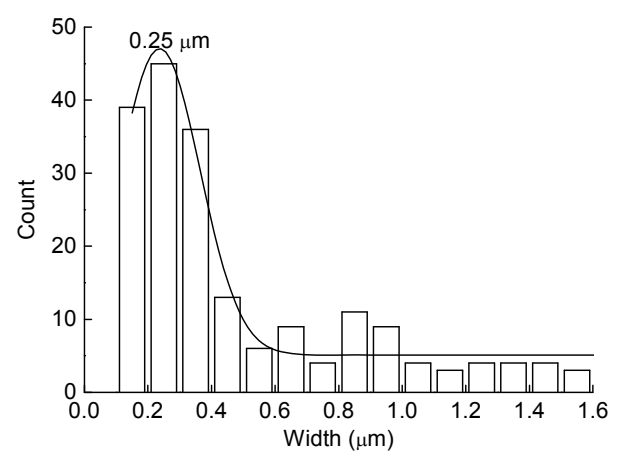

Fig. 10 Interface width distribution functions

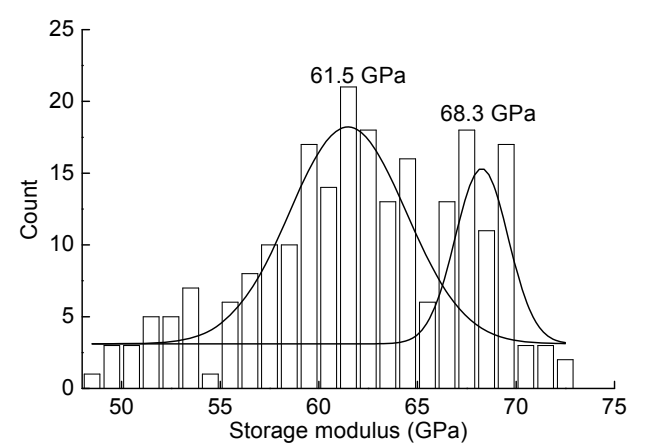

Fig. 11 Interface storage modulus distribution functions

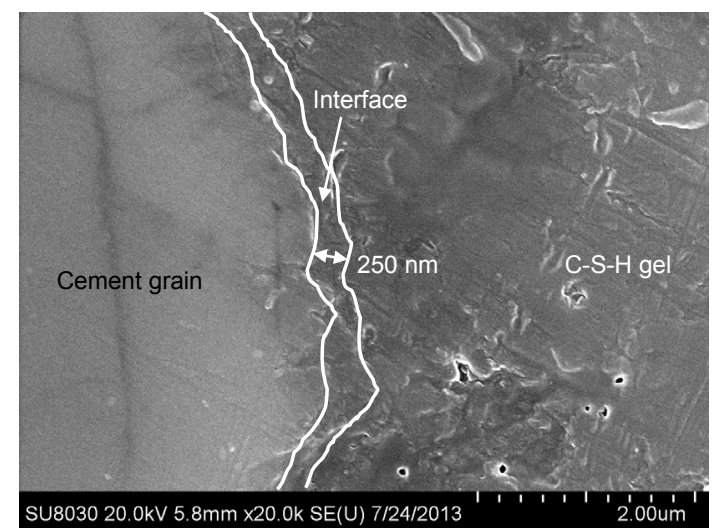

Fig. 12 SEM images of interface between C-S-H gel and cement grain

\section{Conclusions}

The local nanomechanical properties of interface between C-S-H gel and cement grains were obtained by nanoindentation and modulus mapping. Nanoindentation results provided a rough estimate of interface width of less than $5 \mu \mathrm{m}$. One could attribute this large figure to the step size $(3 \mu \mathrm{m})$ used in indentation. The modulus and hardness of the interface were $68 \mathrm{GPa}$ and $3 \mathrm{GPa}$, respectively, as determined by nanoindentation. Modulus mapping yielded an interface width of $250 \mathrm{~nm}$, owing to much higher spatial resolution (around $50 \mathrm{~nm}$ ) of the viscoelastic modulus imaging. The packing density in the interface was non-uniform as two peaks of value 61.5 $\mathrm{GPa}$ and $68.3 \mathrm{GPa}$ were observed for the storage modulus distribution. This interface could be regarded as a dense layer around cement grains.

\section{References}

Acker, P., 2001. Micromechanical analysis of creep and shrinkage mechanisms. Creep, Shrinkage and Durability Mechanics of Concrete and Other Quasi-brittle Materials, Elservier, London, UK.

Balooch, G., Marshall, G.W., Marshall, S.J., et al., 2004. Evaluation of a new modulus mapping technique to investigate microstructural features of human teeth. Journal of Biomechanics, 37(8):1223-1232. [doi:10. 1016/j.jbiomech.2003.12.012]

Constantinides, G., Ulm, F.J., 2004. The effect of two types of C-S-H on the elasticity of cement-based materials: results from nanoindentation and micromechanical modeling. Cement and Concrete Research, 34(1):67-80. [doi:10.1016/S0008-8846(03)00230-8]

Constantinides, G., Ulm, F.J., 2007. The nanogranular nature of C-S-H. Journal of the Mechanics and Physics of Solids, 55(1):64-90. [doi:10.1016/j.jmps.2006.06.003]

Constantinides, G., Ulm, F.J., van Vliet, K., 2003. On the use of nanoindentation for cementitious materials. Materials and Structures, 36(3):191-196. [doi:10.1007/BF02479557]

Constantinides, G., Chandran, K.S.R., Ulm, F.J., et al., 2006. Grid indentation analysis of composite microstructure and mechanics: principles and validation. Materials Science and Engineering: A, 430(1-2):189-202. [doi:10. 1016/j.msea.2006.05.125]

Davydov, D., Jirásek, M., Kopecký, L., 2011. Critical aspects of nano-indentation technique in application to hardened cement paste. Cement and Concrete Research, 41(1):2029. [doi:10.1016/j.cemconres.2010.09.001]

DeJong, M.J., Ulm, F.J., 2007. The nanogranular behavior of $\mathrm{C}-\mathrm{S}-\mathrm{H}$ at elevated temperatures (up to $700{ }^{\circ} \mathrm{C}$ ). Cement and Concrete Research, 37(1):1-12. [doi:10.1016/j. cemconres.2006.09.006] 
Jennings, H.M., Thomas, J.J., Gevrenov, J.S., et al., 2007. A multi-technique investigation of the nanoporosity of cement paste. Cement and Concrete Research, 37(3):329336. [doi:10.1016/j.cemconres.2006.03.021]

Jones, C.A., Grasley, Z.C., Ohlhausen, J.A., 2012. Measurement of elastic properties of calcium silicate hydrate with atomic force microscopy. Cement and Concrete Composites, 34(4):468-477. [doi:10.1016/j.cemconcomp. 2011.11.008]

Kawashima, S., Hou, P., Corr, D.J., et al., 2013. Modification of cement-based materials with nanoparticles. Cement and Concrete Composites, 36:8-15. [doi:10.1016/j. cemconcomp.2012.06.012]

Miller, M., Bobko, C., Vandamme, M., et al., 2008. Surface roughness criteria for cement paste nanoindentation. Cement and Concrete Research, 38(4):467-476. [doi:10. 1016/j.cemconres.2007.11.014]

Mondal, P., Shah, S.P., Marks, L.D., 2007. A reliable technique to determine the local mechanical properties at the nanoscale for cementitious materials. Cement and Concrete Research, 37(10):1440-1444. [doi:10.1016/j.cemconres. 2007.07.001]

Mondal, P., Shah, S.P., Marks, L.D., 2008. Nanoscale characterization of cementitious materials. Materials Journal, 105(2):174-179. [doi:10.14359/19758]

Oliver, W.C., Pharr, G.M., 1992. An improved technique for determining hardness and elastic modulus using load and displacement sensing indentation experiments. Journal of Materials Research, 7(6):1564-1583. [doi:10.1557/ JMR.1992.1564]

Oliver, W.C., Pharr, G.M., 2004. Measurement of hardness and elastic modulus by instrument indentation: advances in understanding and refinements to methodology. Journal of Materials Research, 19(1):3-20. [doi:10.1557/jmr. 2004.19.1.3]

Sorelli, L., Constantinides, G., Ulm, F.J., et al., 2008. The nano-mechanical signature of ultra high performance concrete by statistical nanoindentation techniques. Cement and Concrete Research, 38(12):1447-1456. [doi:10.1016/j.cemconres.2008.09.002]

Uskokovic, P.S., Tang, C.Y., Tsui, C.P., et al., 2007. Micromechanical properties of a hydroxyapatite/poly-L-lactide biocomposite using nanoindentation and modulus mapping. Journal of the European Ceramic Society, 27(2-3): 1559-1564. [doi:10.1016/j.jeurceramsoc.2006.04.122]
Vandamme, M., Ulm, F.J., Fonollosa, P., 2010. Nanogranular packing of C-S-H at substochiometric conditions. Cement and Concrete Research, 40(1):14-26. [doi:10. 1016/j.cemconres.2009.09.017]

Velez, K., Maximilien, S., Damidot, D., et al., 2001. Determination by nanoindentation of elastic modulus and hardness of pure constituents of Portland cement clinker. Cement and Concrete Research, 31(4):555-561. [doi:10. 1016/S0008-8846(00)00505-6]

Xiao, J.Z., Li, W.G., Sun, Z.H., et al., 2013. Properties of interfacial transition zones in recycled aggregate concrete tested by nanoindentation. Cement and Concrete Composites, 37:276-292. [doi:10.1016/j.cemconcomp. 2013.01.006]

Xu, J., Yao, W., 2011. Nano-scratch as a new tool for assessing the nano-tribological behavior of cement composite. Materials and Structures, 44(9):1703-1711. [doi:10. 1617/s11527-011-9728-7]

\section{中文概要}

题 目: 采用纳米压痕及动态模量图研究 C-S-H 凝胶/水 泥颗粒界面的纳米力学性能

目 的：揭示水泥基材料中 C-S-H 凝胶/水泥颗粒界面的 尺寸及微观力学特性, 为从纳米尺度理解水泥 基材料的性能提供依据。

创新点: 采用动态模量图技术对 C-S-H 凝胶/水泥颗粒界 面微区的尺度及力学行为进行研究, 借助动态 模量图的高分辨性, 可获得该微区精确且有效 的信息。

方 法: 对比利用纳米压痕及动态模量图对 C-S-H 凝胶/ 水泥颗粒界面进行研究。

结 论: 纳米压痕仅能粗略估计界面微区的尺寸及力学 参量, 相比之下, 动态模量图的分辨率要高出 2 个数量级 (表 2), 因此可获得更精确的测量 值。C-S-H 凝胶/水泥颗粒界面的尺寸在 $250 \mathrm{~nm}$ 左右, 模量值介于 $60 \mathrm{GPa}$ 和 $70 \mathrm{GPa}$ 之间。此界 面区可认为是包覆水泥颗粒周围的一层紧密的 水化层结构, 其致密性将阻止内部水泥的进一 步水化。

关键词: 水泥基材料; 界面; 纳米力学特性; 动态模量图 